\title{
RELAÇÃO ENTRE MORBIDADE RESPIRATÓRIA DE CRIANÇAS E VARIÁVEIS METEOROLÓGICAS NO MUNICÍPIO DE URUGUAIANA/RS
}

\author{
Luiz E. Medeiros ${ }^{1}$ e Anderson S. Nedel ${ }^{2}$ \\ ${ }^{1}$ Departamento de Física, Faculdade de Meteorologia - UFSM \\ ${ }^{2}$ Faculdade de Meteorologia - Universidade Federal de Pelotas - UFPel
}

\section{RESUMO}

Neste trabalho, é investigado se existe relação entre as condições meteorológicas e a ocorrência de doenças respiratórias em crianças menores que cinco anos. Para tal, são estabelecidas correlações entre índice de conforto térmico- temperatura efetiva em função do vento $\left(T E_{v}\right)$, temperatura do ponto de orvalho $\left(T_{d}\right)$, e temperatura mínima $\left(T_{\min }\right)$ com morbidade respiratória (internação hospitalar). No período de junho à setembro, ocorre o maior número de internações. Dentre as variáveis meteorológicas escolhidas, $T_{d}$ apresenta correlação ligeiramente maior com morbidade.

\section{INTRODUÇÃO}

Vários estudos têm verificando as influências do Tempo e do clima na saúde da população humana. LECHA (1998) relacionou diversos tipos diários de tempo com a ocorrência de doenças respiratórias e mostrou que os dias frios e muito frios estavam relacionados ao aumento de asma brônquica em adultos e crianças. Em um estudo para a cidade de Buenos Aires, Argentina, RUSTICUCCI et al. (2001), mostraram que, durante o inverno, houve um aumento de aproximadamente 17\% nas visitas por vários tipos de complicações (respiratória, cardiovascular e dor no peito, neurológica e psicopatológica, infecções, entre outras...), ao passo que no verão, houve um maior aumento nas complicações digestivas, de pele e alérgicas. Maior admissão por problemas respiratórios foi observada um dia após o pico de $T_{d}$. Esses estudos corroboram estudos no Brasil (COELHO, 2007). Tendo em vista estes resultados já encontrados, aqui são investigadas possíveis relações entre algumas variáveis meteorológicas e morbidade respiratória de crianças entre 0 e 4 anos para o município de Uruguaiana, RS para o período de 1998 à maio/2013. 


\section{MATERIAIS E MÉTODOS}

Para o estudo, foram utilizados dados de temperatura, umidade, vento, e pressão do Instituto Nacional de Meteorologia (INMET), e dados de internações hospitalares por doenças respiratórias obtidos do Banco de Dados do Sistema Único de Saúde (DATASUS). Com os dados do INMET, determinou-se o índice de conforto térmico Temperatura Efetiva $\left[T E_{v}=\right.$ 37-(37-T)/[0.68-0.0014UR +1/(1.76+1.4V 0.75$)]-0.29 T(1-U R / 100)]$, onde $T$ é a temperatura do $\operatorname{ar}\left({ }^{\circ} \mathrm{C}\right), U R$ é a umidade relativa do ar $(\%)$ e $V$ a velocidade do vento. $T E_{v}$ é a temperatura efetiva em função do vento $\left({ }^{\circ} \mathrm{C}\right)$ e representa a ação (trocas de calor sensível e latente) conjunta das variáveis meteorológicas sobre o ser humano. Também foram verificadas as relações de $T_{\min }$ e $T_{d}$ com as internações.

\section{RESULTADOS}

O maior número de internações se dá nos meses de inverno, de junho à setembro (Fig. 1). Este padrão é mais definido para pneumonia e gripe, que são doenças típicas de tempo frio,

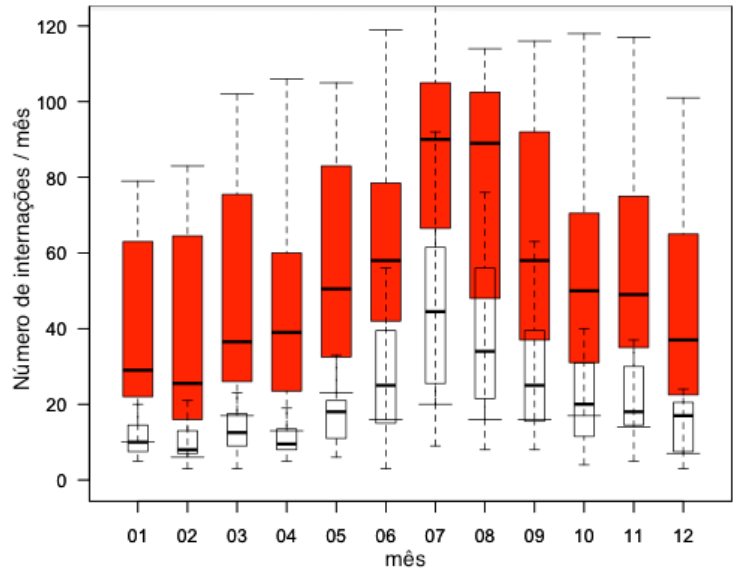
representando $\approx 45 \%$ no inverno, e $\approx 30 \%$ nas demais estações do total de internações.

Figura. 1: Distribuição mensal de morbidade hospitalar devido a todos os tipos de doenças (caixas vermelhas) e devido somente a pneumonia e gripe (caixas vazias).

A série temporal de morbidade mensal, conjuntamente com as séries mensais médias de $T E_{v}, T_{d}$, e $T_{\min }$ indicam que há uma relação entre as condições meteorológicas e morbidade hospitalar (Fig. 2). Esta relação é mais clara para o período de 2002 à 2009. O número de internações por mês aumentou no decorre da série total, sendo que de 1998 à 2001 foi 25 (desvio padrão $\sigma=11$ ), de 2002 à 2009 foi 59 $(\sigma=32)$ e de 2010 à maio/2013 foi $83(\sigma=17)$. Talvez isso se deva a melhorias no serviço prestado pelo Sistema Único de saúde (SUS), pois a população entre 0 e 4 anos de idade diminui (13,000 - 9,500 habitantes) no período entre 1998 e 2012. O menor valor da razão entre a média de morbidade mensal e desvio padrão de morbidade mensal para o período de 2002 à 2009, mostra o efeito mais pronunciado das estações na quantidade de internações 
para o período. As correlações entre morbidade e $T E_{v}, T_{d}$, e $T_{\min }$ (Tab. 1) mostram que existe influência das condições meteorológicas na doenças respiratórias, entretanto este resultado é mais claro para o período de 2002 à 2009.

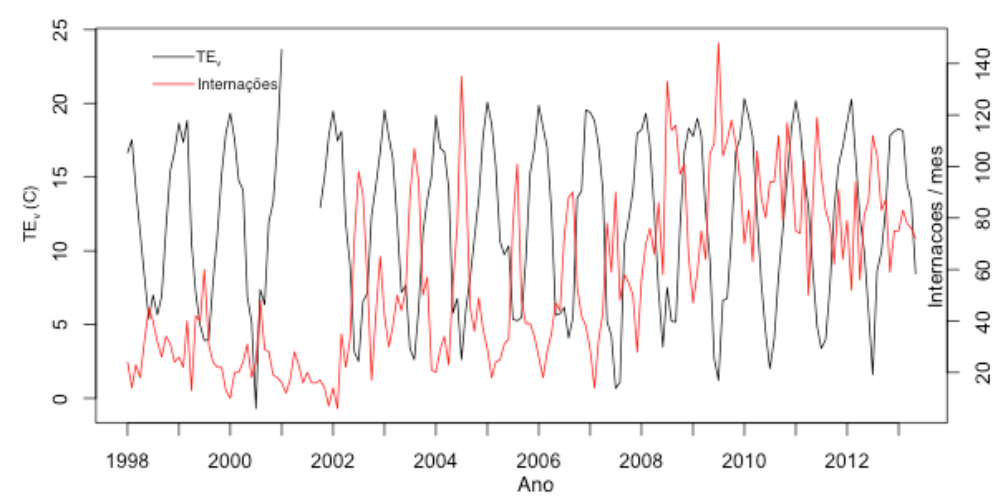

Figura 2: Número total de internações por mês devido a todos os tipos de doenças respiratórias (linha vermelha) e valor médio mensal de $T E_{v}$ (linha preta). Note que os valores médios mensais de $T E_{v}$ e $T_{d}$ foram calculados a partir do valores mínimos diários.

Tabela 1: Correlação entre o número de internações /mês e $T E_{v}, T_{d}, e T_{m i n}$.

\begin{tabular}{|c|c|c|c|c|}
\hline & \multicolumn{4}{|c|}{ Correlações entre $T E_{v}, T_{d}, T_{\min }$ e morbidade } \\
\hline & \multicolumn{2}{|c|}{ Todas doenças respiratórias } & \multicolumn{2}{|c|}{ Pneumonia e Influenza } \\
\hline Período & $1998-2013$ & $2002-2009$ & $1998-2013$ & $2002-2009$ \\
\hline$T E_{v}$ & -0.40 & -0.59 & -0.55 & -0.63 \\
\hline$T_{d}$ & -0.48 & -0.64 & -0.53 & -0.63 \\
\hline$T_{\min }$ & -0.44 & -0.61 & -0.52 & -0.60 \\
\hline
\end{tabular}

\section{CONCLUSÃO}

As correlações entre morbidade respiratória e as variáveis meteorológicas (Tab. 1) mostram que as condições da atmosfera, representadas pelas variáveis $T E_{v}, T_{d}$, e $T_{\min }$, exercem influência na ocorrência de doenças respiratórias em crianças menores do que cinco anos. Toda via, a variável $T E_{v}$ a qual leva em conta os efeitos combinados da temperatura, umidade e do vento não apresentou uma correlação melhor com morbidade do que $T_{d}$ e $\mathrm{T}_{\min }$. Talvez se tivessem sido analisados casos de internações em escalas de tempo igual ou menores a uma semana, o que é comparável a escala de tempo entre a passagem de frentes, $T E_{v}$ apresentaria correlações maiores com morbidade. Nesta escala de tempo, poder-se-ia correlacionar as internações que aconteceriam logo após uma mudança significativa nas condições da atmosfera. $\mathrm{O}$ fato de que o número de internações/mês não se manteve 
constante ao longo do período total do estudo (1998 - maio/2013) e mais a possibilidade de diagnósticos médicos errôneos mascaram de certa maneira as correlações apresentadas.

Agradecimentos- Luiz E. Medeiros agradece o suporte da CAPES/FAPERGS Proc. No 279325.51/12-4. Os autores também agradecem ao INMET e ao SUS pela disponibilização dos dados.

\section{REFERÊNCIAS}

COELHO, M.S.S.Z. Uma análise estatística com vistas à previsibilidade de doenças respiratórias em função das condições meteorotrópicas na cidade de São Paulo. 2007. Tese de doutorado, IAG-USP, 2007.

LECHA, L.B. Biometeorological classification of daily weather types for the humid tropics. International Journal of biometeorology, Vol 42, pp 77-83, 1998.

RUSTICUCCI, M; HARRIS, M; ACOSTA E. Relación entre las causas de internación en un ospital general y las condiciones meteorológicas durante el año 1995. Actas VII Congreso Argentina de Meteorologia, VII Congreso Latinoamerricano y Ibérico de Meteorologia. Centro Argentino de Meteórologos. pp 459-460, 2001. 